https://doi.org/10.48009/1_iis_2007_134-138

\title{
TEACHING AN APPLIED BUSINESS INTELLIGENCE COURSE
}

\author{
Stevan Mrdalj (smrdalj@emich.edu)
}

\begin{abstract}
This paper reports on the development of an applied Business Intelligence (BI) course for a graduate program. The course provides students with working knowledge of the concepts, techniques, and tools to provide effective business intelligence. Students learn how to leverage data warehousing and data mining to establish a competitive advantage and solve business problems faster by using SAP's online analytical processing, data warehousing and data mining tools. In addition, this course provides a detailed overview and strategic analysis of the available data mining and warehousing technologies. Students also learn how to compare different data mining technologies, and understand how they fit into the overall business processes.
\end{abstract}

Keywords: Business Intelligence, Data Mining, Data Warehousing, SAP BW, Curriculum

\section{INTRODUCTION}

Many organizations struggle to provide the right information to the right people at the right time, to help them make the right decisions. People at all levels in an organization need access to critical business information, and to have the ability to analyze and share that information with suppliers, partners, and customers. With aggressive competitors and highly dynamic markets, "gut feelings" and "trial and error" are not effective for managing an enterprise. Business users throughout many organizations need Business Intelligence (BI) for quick-and-easy access to information, to make timely and accurate decisions. The BI is a systematic approach to automating and improving high-volume operational and managerial decisions. It promotes a shift from speculative guessing to informed and factbased decision making. Hence, business users and information assets are more fully leveraged, driving enhanced profitability, increased market share and improved customer service.

The basic challenge in teaching a BI course is its high overlap with statistics, databases and various business disciplines. Such a course can be taught in many different ways. Since BI is relatively new to the CIS curriculum, there is a need to discuss various approaches in teaching a BI course.
Some of the first experimental undergraduate data mining course development is reported by $\mathrm{Lu}$ and Bettine [7]. Paper by Banks et al. [1] describes teaching data mining courses as "an exciting addition to the curriculum at the senior/graduate level" courses that provide the opportunity to apply computer related education to various domains and applications. A very good tutorial on data mining that can be used by educators as an introduction to business intelligence is presented by Roiger [10]. The typical structure of the data warehousing and data mining course is well described by Fang and Tuladhar [6], as well as by Watson [11]. One of the teaching approaches by reading research papers and developing algorithms is reported by Musicant [9].

This paper presents the structure and components of a $\mathrm{BI}$ course that is designed to appeal to the master students of the CIS program as well as the MBA students selecting the CIS concentration. Specifically, this course focuses on "business aspects" of data mining and data warehousing without a very intensive study of mining algorithms. The main focus is on having students learn how to answer today's business questions like:

- Which customers are contributing to our profitability and which ones are not?

- Which assortment of products produces incremental product lift rather than cannibalization?

- Which services are most profitable to my organization based on the costs of retaining the customer?

This is achieved by incorporating hands-on in-class lab activities, where students are enabled to immediately apply presented concepts and to reinforce their understanding. In addition, business oriented assignments and challenges help students to closely identify with real-world problems and BI applications. The closest approach to the one in this paper is reported by Chawala [3]. That course is also motivated from the "real-world" usage of data mining except that it is computer science oriented. In addition, Cawala reports that his course received positive student feedback on the course structure and teaching methods very similar to ours. 
This course utilizes the SAP Business Information Warehouse (SAP® BW) which provides a complete business intelligence suite with specialized tools for reporting, query and analytics. There are many other tools that are uses for such courses, and are reported in curriculum related papers, like SAS Enterprise Miner [4], Weka [3,] and Microsoft SQL Server [6].

\section{COURSE COMPETENCIES}

It is preferred that students taking this course have the knowledge of relational data modeling and query design techniques. This course provides students with an overall experience in business analytics, data mining and data warehousing. The objectives of this course are described with the following competencies.

- Understanding the role of data in supporting management decision making.

- $\quad$ Understanding the distinctions between a transactional database and a data warehouse.

- $\quad$ Describing and explain on-line reporting systems.
- Understanding the fundamentals of data mining technologies and its application in business.

- Knowledge on how to select and use appropriate data mining algorithms and techniques.

- $\quad$ Applying data mining techniques to organizational data

- Developing a data mining application.

- Applying data warehousing techniques to organizational data

- Understanding various data warehousing models.

- Know how to apply various tools that utilize a data warehouse.

- Knowledge of data warehousing construction methods.

- Developing a data warehouse application.

\section{COURSE OUTLINE}

The course is structured into three parts: introduction to BI with online analytical processing, data mining and data warehousing. Table 1 shows a tentative schedule of topics and assignments to be covered in this course.

Table 1. Course outline

\begin{tabular}{|c|l|l|}
\hline Week & \multicolumn{1}{|c|}{ Topic } & \multicolumn{1}{|c|}{ Labs } \\
\hline 1 & Introduction to BI & \\
\hline 2 & $\begin{array}{c}\text { Data Warehousing } \\
\text { Data Mining }\end{array}$ & SAP BW Navigation \\
\hline 3 & SAP and Corporate Information Warehouse Factory & \\
\hline 4 & $\begin{array}{l}\text { SAP BI Overview } \\
\text { SAP Business Contents }\end{array}$ & \\
\hline 5 & Analytic Applications & Query Design \\
\hline 6 & Association Analysis & On-Report Analysis \\
\hline 7 & Clustering & Association Analysis Tutorial \\
\hline 8 & Decision Trees & Clustering Tutorial \\
\hline 9 & ABC Classification & Decision Trees Tutorial \\
\hline 10 & Scoring & ABC Classification Tutorial \\
\hline 11 & Putting It All Together - Case Study & Scoring Tutorial \\
\hline 12 & Extraction, Transfer and Loading (ETL) & Creating an InfoCube \\
\hline 13 & BW Administration & Loading Data into InfoCube \\
\hline 14 & Group Project Presentation & \\
\hline 15 & Group Project Presentation & \\
\hline & & \\
\hline
\end{tabular}




\section{TEACHING METHODS}

The course structure blends the theory and practice based on the "real-world" usage of the data mining and data warehousing. This course uses the SAP BW business intelligence tools. The students' feedback on using this tool is provided in the conclusion. The course uses a textbook by Kevin McDonald, Andreas Wilmsmeier, David C. Dixon, W. H. Inmon [8] as a required textbook. The primary reason for adapting that textbook is its coverage of the SAP BW tools and very good practical discussions on using various tools. Students are also encouraged to read other relevant texts $[2,5]$.

The following are teaching methods used in this course:

Lectures: Important material from the text and outside sources are covered in class using PowerPoint slides. The slides are available online as lecture notes. Students are encouraged to take careful notes as not all material can be found in the texts or readings. Students are also encouraged to contribute relevant material and examples. During the lecture portion, all concepts are explained at length, and then they are reinforced by using in-class lab activities.
In-class Lab Activities: This course is conducted in a computer classroom with access to the SAP server. Lab activities are designed to help students gain hands-on skills in using a variety of development tools. Given the complexity of the SAP BW tools, many concepts and procedures are not immediately clear to the students. Therefore, detailed in-class lab tutorials are developed. An example of the tutorial slides is shown in Figure 1. Using such slides, the step-by-step procedure on how to solve a given problem is explained first, and then the students are given a bussines problem to solve. These problems are typically assigned in the following form: "Is it true that customer discount is an important factor in determining churn of our New York male customers whereas marketing cost is an important factor in determining churn of our Washington DC female customers?". Such activities really helped the students to understand underlining concepts and how to apply them. These exercises also helped the students to develop analytical and problem solving skills.

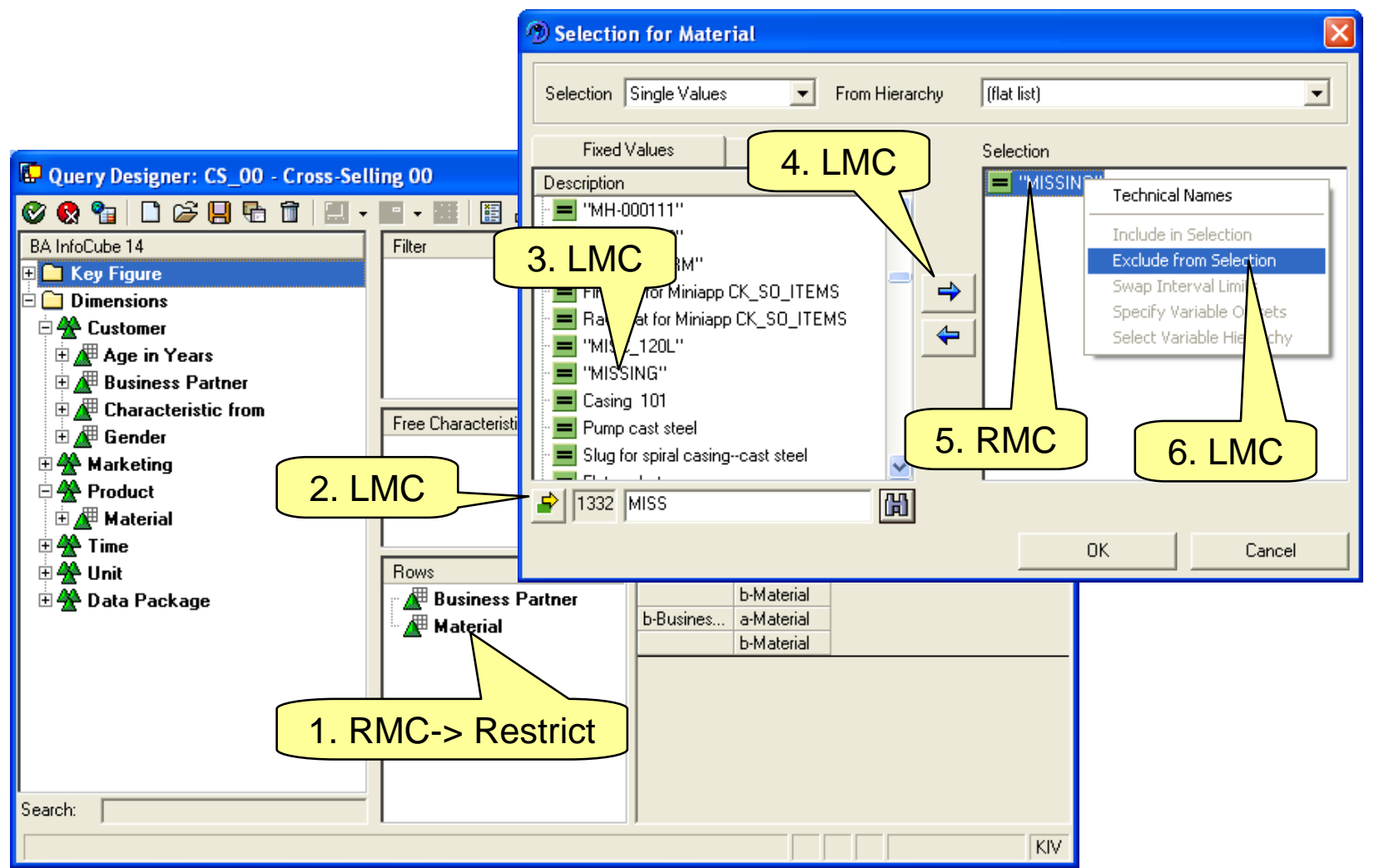

Figure 1. Sample tutorial slide 
Homework Assignments: Periodical homework assignments are assigned to further reinforce the knowledge discovery process and to ecourage the use of the supplemental material found in the text. The assignments include experimentation using various SAP demo InfoCubes, comparison of different methods and business interpretations of results.

Class Project: A group project which involves building a business intelligence application is assigned after all data mining tecniqes are discussed. The students are asked to divide into groups that consist of 2-3 members. Each group needs to define, develop and implement its own business case that includes the following:

- Define the business issue:

- Identify the business opportunity.

- Define the problem.

- Knowledge discovery process:

- Define which data sources will be used (SAP Demo InfoCubes)

- Extract and preprocess the data
- $\quad$ Evaluate the data

- $\quad$ Select the data mining techniques

- Perform data mining

- Interpret the results

- Interpret and translate the mining results into "actionable business strategies".

The students are required to use several data mining techniques in creating their projects. Several sample project strategies are presented in class, as shown in Figure 2, and fully discussed with students. Each group is required to submit a 1-2 page project proposal with their business problem, project strategy and what potential results they expect to accomplish. This allows the instructor to provide early feedback to the students and in some cases to discover major flaws in the proposed project strategy. Beside the final project report, the students are required to do inclass project presentations. These presentations are followed by a peer-review discussion among students and the instructor.

\section{Decision Trees}
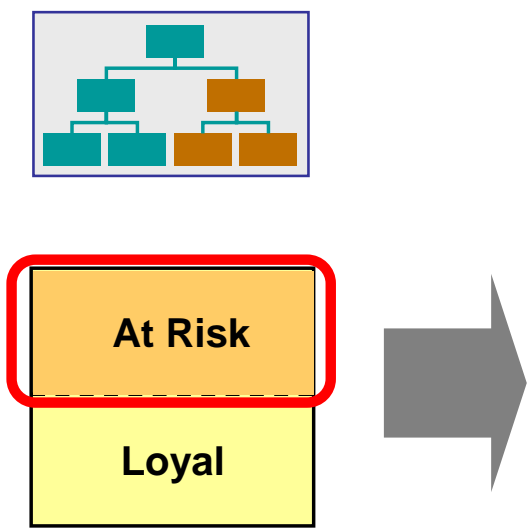

Goal:

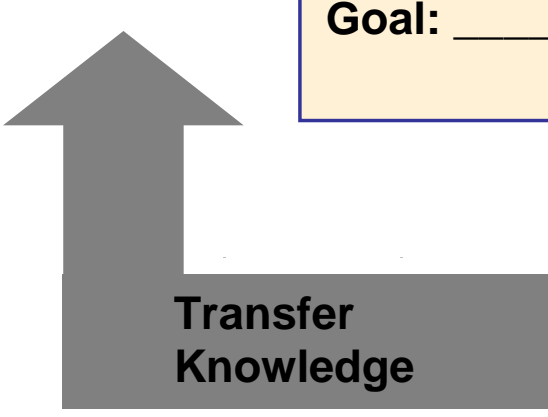

Business Strategy
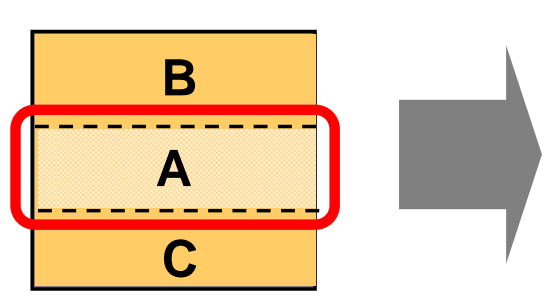

ABC Classification
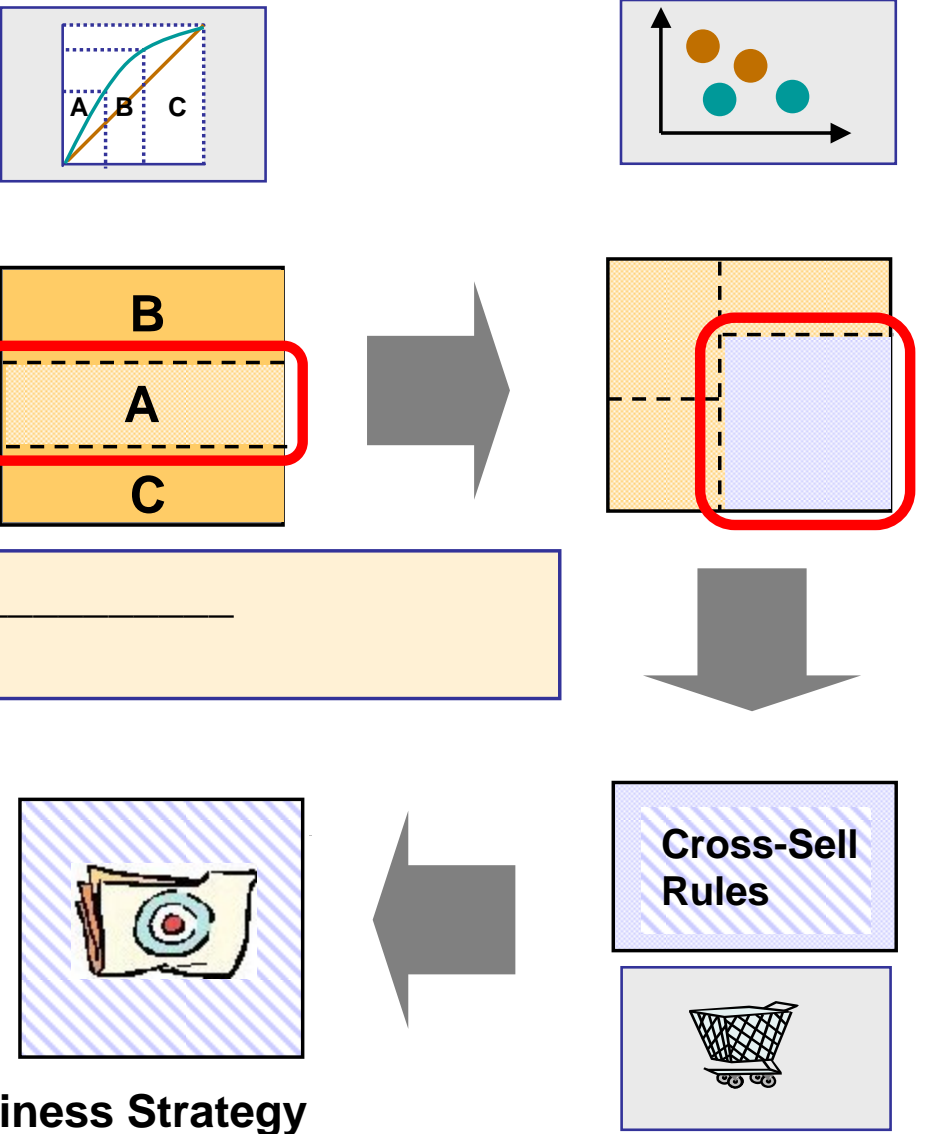

Association Analysis 
Figure 2. A sample project strategy.

The project rules include the following. Each group must keep a log of their meetings which contains the following information: Date, Time, Duration, Topic, Activity, members present, and comments. Each member must provide a complete performance evaluation of the other members of the team. Each team will receive a final grade on the project, however, individual member's grades for the project may vary depending on their performance on the project. Individual project grades will be based on team evaluations and instructor's assessment of a member's contribution to the project.

\section{CONCLUSIONS}

This course has been offered twice and it was very clear from the students' responses that it is becoming one of the most popular MS-CIS graduate courses. The students found the use of SAP BW and the applied nature of this course extremely useful for their careers. As one student pointed out "this course is good mix of theory and practices". Another student described the course as "well integrated real-world examples into lectures”. Several students expressed that "the course structure and the course content that relates to the real business world" is what they liked the most about this course. Some students suggested providing bigger variety of data samples for them to explore and experiment.

Based upon the experience in teaching such a course, we concluded that incorporation of real-world applications, use of hands-on lab activities and a class project made this class exciting what otherwise used to be dry presentations of the analytical data mining techniques. At the same time it is important to point out that preparation for such a course is extremely time consuming.

\section{REFERENCES}

1. Banks, D. L., Dong, G., Liu, H., and Mandvikar, A. (2004). Teaching Undergraduates Data Mining Engineering Programs. Proceedings of the 34th ASEE/IEEE Frontiers in Education Conference,

2. Berry, M.J. A. \& Linoff, G.S., (2004) Data Mining Techniques: For Marketing, Sales, and Customer Relationship Management, 2nd Edition, Wiley.

3. Chawla, N. V., (2005). Teaching Data Mining By Coalescing Theory and Applications, Proceedings of the 35th ASEE/IEEE Frontiers in
Education Conference, Indianapolis, IN, S1J-1723.

4. Dickey, D. A., (2005). Teaching Data Mining in a University Environment, Proceedings of the SUGI 30 Conference, Philadelphia, Pennsylvania, 1-10.

5. Eggar, N. (2004). SAP BW Professionsl SAP Press.

6. Fang, R. \& Tuladhar, S. (2006). Teaching data warehousing and data mining in a graduate program of information technology, Journal of Computing Sciences in Colleges, 21(5), 137-144.

7. Lu, Y, \& Bettine, J, (2003). Data Mining: An Experimental Undergraduate Course. Journal of Computing Sciences in Colleges, 18(3), 81-86

8. McDonald, K., Wilmsmeier, A., Dixon, D.C. \& . Inmon, W. H, (2002). Mastering the SAP Business Information Warehouse. Wiley.

9. Musicant, D. R. (2006). A data mining course for computer science, ACM SIGCSE Bulletin, 38(1), 538-542.

10. Roiger, R. J. (2005). Teaching an introductory course in data mining, ACM SIGCSE Bulletin , 37(3). 415-

11. Watson, H. J. (2006). BI and Data Warehousing in Universities, Business Intelligence Journal, 11(3), 4-6. 